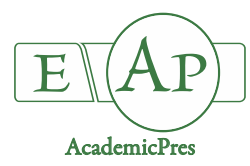

Available online: www.notulaebotanicae.ro

\title{
Seed Vigour Tests to Estimate Seedling Emergence in Cress (Lepidium sativum L.) Seed Lots
}

\author{
Ibrahim DEMIR ${ }^{1}$, Burcu B. KENANOGLU ${ }^{2}$, Eren ÖZDEN ${ }^{3 *}$ \\ ${ }^{1}$ University of Ankara, Faculty of Agriculture, Department of Horticulture, 061 10, Ankara, Turkey; demir@agri.ankara.edu.tr \\ ${ }^{2}$ Usak University, Faculty of Natural and Agricultural Science, Horticulture Department, Usak, Turkey; burcu.kenanoglu@usak.edu.tr \\ ${ }^{3}$ Igdir University, Faculty of Agriculture, Department of Horticulture, Igdir, Turkey; eren.ozden@igdir.edu.tr ('corresponding author)
}

\begin{abstract}
This work was carried out to estimate field and controlled room seedling emergence potential through seed vigour tests in cress (Lepidium sativum L.) seeds. Early radicle emergence percentages after 12 (RE12h), 24 (RE24h) and 36 (RE36h) hours of germination test, mean germination time, accelerated aging $\left(45^{\circ} \mathrm{C}, 100 \% \mathrm{RH}, 24 \mathrm{~h}\right)$, electrical conductivity (EC) of soaking water $\left(40 \mathrm{ml}, 50\right.$ seeds, $\left.20^{\circ} \mathrm{C}\right)$, after 16 hours $(\mathrm{EC} 16 \mathrm{~h})$ and 24 hours (EC24h), and EC16h and EC24h after accelerated ageing (AA, $45^{\circ} \mathrm{C}, 100 \% \mathrm{RH}, 24 \mathrm{~h}$ ) were tested as vigour tests in ten commercial seed lots of cress. Standard laboratory germination ranged between 88 and $93 \%$. Seeds were sown on two occasions in field and controlled room conditions, and seedling emergence percentages were determined after 30 days in the soil and 14 days in the controlled room. Seedling emergence ranged between 67 and $85 \%$ and 59 and $83 \%$ in the first and second sowings in the field. These values were 75 and $92 \%$ in controlled room sowing. Vigour tests were correlated to seedling emergence potential at various significance levels but RE24h and EC16h showed the highest correlation coefficient values $(\mathrm{p}<0.001)$ in all three sowing conditions as $\mathrm{r}=0.879-0.988$ in RE24h, and $r=0.902-0.962$ in EC16h. Results indicated that early radicle emergence percentages after 24 hours (RE24h) and electrical conductivity value after 16 hours $(\mathrm{EC} 16 \mathrm{~h})$ can be successfully used to estimate the seedling emergence potential of cress seeds in field and controlled room conditions.
\end{abstract}

Keywords: accelerated aging test; electrical conductivity; mean germination time; radicle emergence test; seed vigour Abbreviations: accelerated aging (AA); CRE (Controlled room emergence); electrical conductivity (EC); mean germination time (MGT); radicle emergence (RE); relative humidity $(\mathrm{RH})$; standard germination (SG)

\section{Introduction}

Cress is a leafy vegetable species which, in the Mediterranean region, is sown directly in the open field throughout the year or in plastic tunnels in the winter months. Seeds facing suboptimum conditions such as in early spring (low temperature) or late summer (high temperature) sowings in seed beds result in a decline in emergence potential. The standard laboratory germination test is a measure of seed quality (ISTA, 2017) which may provide information about the seedling emergence capacity of the lots when the sowing environment is favourable. However, this may not necessarily be sufficient to indicate emergence potential when seeds are sown in stress conditions such as low and high temperatures in open field production. Differences in the field emergence percentages and rate of seed lots with high standard laboratory germination are referred to as seed vigour (TeKrony, 2003;
Marcos-Filho, 2015) which comprises various aspects of quality and indicates the stage of seed deterioration

Fast and uniform emergence determines plant size (Demir et al., 2008) in vegetables. Seed lots of low vigour germinate slowly and in turn produce smaller-sized plants. The longer the duration over which emergence takes place in the field, the smaller the plant size (Matthews et al., 2012), resulting in lower yield (Finch-Savage, 1995). Therefore, estimation of seedling emergence potential of such species as cress in which young leaves are consumed provides information on both seed quality evaluation and yield potential in the field (Marcos-Filho, 2015). Emergence prediction can be valuable for open field sowing in the spring and summer months and for controlled environment sowings in a low plastic tunnel in the winter months in cress growing. Seed vigour tests provide additional information on the relative emergence potential of seed lots in unfavourable sowing conditions compared to standard germination tests (TeKrony, 2003). Several such tests have 
882

been used to indicate emergence potential in crop seeds. Among these, accelerated ageing (AA) and electrical conductivity (EC) are widely used (Hampton and TeKrony, 1995). AA is based on differentiating seed lots by testing their germination after a period of controlled ageing. Typically, AA is applied at $41-43{ }^{\circ} \mathrm{C}$ for $48-72$ hours with $100 \% \mathrm{RH}$ (Hampton and TeKrony, 1995). EC is based on the measurement of seed soak water in relation to the seed deterioration level of the seed lots. More recently, mean germination time (MGT) and radicle emergence (RE) tests - early counts of $2 \mathrm{~mm}$ radicle protrusion during standard germination - have been studied and related to seedling emergence percentages and seedling size in many different crop seeds (Matthews and Powell, 2011). Based on a large number of studies on RE tests in various species, it has been validated by ISTA for oil seed rape, radishes and maize (Powell and Mavi, 2016; ISTA, 2017). Even though various seed vigour tests have been used to estimate emergence potential (Marcos-Filho, 2015), research on the use of such tests for cress is very scarce. The present study evaluated the conditions for the application of accelerated ageing (AA), electrical conductivity (EC), radicle emergence (RE) and mean germination time (MGT) tests to commercial seed lots of cress, in relation to seedling emergence in the field and controlled room conditions.

\section{Materials and Methods}

\section{Biologicalmaterials}

A total of ten seed lots of cress (Lepidium sativum L. cv. 'Tere') produced by different companies were obtained from seed retailers. Seed lots were hermetically sealed in aluminium foil packets. Upon receipt, the seed moisture content was determined (ISTA, 2017) and the sealed aluminium foil packets were stored at $5^{\circ} \mathrm{C}$ until use.

\section{Experimental procedures}

Germination tests were carried out at $20{ }^{\circ} \mathrm{C}$ in incubators, for which 50 seeds of each lot were placed between paper towels (Filtrak, Germany) $(20 \mathrm{~cm} \times 20 \mathrm{~cm})$, and wetted with $10 \mathrm{ml}$ of distilled water. The germination tests were conducted with four replicates of 50 seeds in the dark. The paper towels were rolled and placed in plastic bags to prevent water loss during the test. RE (radicle emergence, $2 \mathrm{~mm}$ ) was calculated in frequent counts of radicle emergence after 12, 24 and 36 hours during the germination test. These counting times were determined in preliminary tests. Subsequently, daily counts were carried out up to ten days. At the final count, ten days after the commencement of the test, the seedlings were classified as either normal or abnormal (ISTA, 2017). Normal seedling percentages in the final count were considered as standard germination (SG).

The mean germination time (MGT, days) was calculated using the formula

$\mathrm{MGT}=\sum \mathrm{n} . \mathrm{t} / \sum \mathrm{n}$

where $\mathrm{n}=$ number of seeds newly germinated $(2 \mathrm{~mm}$ radicle emerged) at time $t$

$\mathrm{t}=$ days from planting, $\sum \mathrm{n}=$ final germination.

For the accelerated aging test (AA), $40 \mathrm{ml}$ of distilled water was added to each plastic aging box $(11 \times 11 \times 4 \mathrm{~cm})$ and 300 seeds were placed on a monolayer cheese cloth placed on a wire mesh tray $(10 \times 10 \times 3 \mathrm{~cm})$ inside the box (Hampton and TeKrony, 1995). Cheese cloth was used on the mesh to prevent seeds from dropping into the water since they are very small. Seeds were aged at $45^{\circ} \mathrm{C}$ for 24 hours at $100 \%$ relative humidity in the dark. After that, the aged seeds were dried on the laboratory bench for about three hours. Then, the standard germination test was conducted on four replicates of 50 seeds, using normal seedling (well-developed cotyledons, no missing parts of the seedling) for assessment (ISTA, 2017). The remaining 100 seeds were used for electrical conductivity measurements (EC after AA) after aging.

In electrical conductivity measurements, two replicates of 50 unaged (EC) and aged (EC after AA) seeds were weighed $(0.0001 \mathrm{~g})$ and soaked in $40 \mathrm{ml}$ of distilled water for 24 hours at $20^{\circ} \mathrm{C}$ in the dark. The distilled water that was used for soaking was kept at $20^{\circ} \mathrm{C}$ overnight to equalize the temperature. EC was measured at 16 and 24 hours in unaged (EC) and aged cress seeds (EC after AA). The electrical conductivity of seed soak water was measured using a conductivity meter (Schott-Gerate $\mathrm{GmbH}$, Hofheim) and expressed as $\mu \mathrm{Scm}^{-1} \mathrm{~g}^{-1}$.

For controlled room emergence test (CRE), seeds (four replicates of 50 seeds/lot) were sown $2 \mathrm{~cm}$ deep in peat moss (Plantaflor-Humus, Verkaufs-GmBH, Germany) in seedling trays $(32 \times 20 \times 6 \mathrm{~cm})$ and placed in an incubator at $20 \pm 2{ }^{\circ} \mathrm{C}$. Light was provided at seedling level by cool fluorescent lamps $\left(72 \mu \mathrm{Mm}^{-2} \mathrm{~s}^{-1}\right)$ for 16 hours a day. The relative humidity in the room was kept over $70 \%$ in order to eliminate evaporation from the surface. The number of emerged seedlings (unfolding cotyledons on the surface) was counted daily up to 14 days, and normally-developed seedling percentages were calculated.

For the field emergence test (FE), seeds (four replicates of 100 seeds / lot) were sown $2 \mathrm{~cm}$ deep in the experimental field of the Department of Horticulture, Faculty of Agriculture, University of Ankara, Turkey, on 4 April 2017 and 25 April 2017. The soil was a sandy loam (pH: 7.57, N: $0.09, \mathrm{P}_{2} \mathrm{O}_{5}: 5.5 \%$, K: $0.16 \%$, Na: $0.41 \%$, Ca: $6.7 \%$, organic matter: $1.1 \%)$. Daily minimum and maximum soil temperatures were recorded throughout both sowings and varied between 7 and $28{ }^{\circ} \mathrm{C}$. The number of seedling emergences assessed to have occurred when the cotyledons had unfolded above the surface was counted daily until 30 days after sowing.

\section{Statistical procedures}

Statistical analysis was conducted using the Statistical Package for Social Sciences (SPSS) by using analyses of variance. Mean separation was made at the $5 \%$ level by the Duncan multiple range test. Correlation coefficients ( $r$ ) of vigour tests with seedling emergence performance in controlled room and field conditions were also calculated at various significance levels.

\section{Results}

Initial standard germination percentages (percentages of normally developed seedlings obtained from commercial source) ranged from 88 and $93 \%$. All seed lots had above $90 \%$ of standard germination except lot 10 which had $88 \%$. 
The standard germination values were well above the commercially acceptable level of $75 \%$ in cress seeds. RE test percentages ranged between 32 and $79 \%$ at 12 hours, 60 and $93 \%$ at 24 hours, and 70 and $97 \%$ at 36 hours (Table 1). As germination time extended, the radicle percentages increased. Mean germination time values ranged between 26 hours and 38 hours. The accelerated aging test (AA) produced germination percentages amongst the lots that were distributed over a large range, (35 and 77\%) indicating differences in vigour (Table 2). Three lots had over $70 \%$ of germination, four lots had over $60 \%$, and the remaining three lots had lower values of 55, 49 and 35\% after aging. Electrical conductivity readings of solute leakage of ten lots after 16 hours ranged between 287 and $356 \mu \mathrm{Scm}^{-1} \mathrm{~g}^{-1}$. Twenty-four hours later, the conductivity values of leakage were increased to between 352 and $497 \mu \mathrm{Scm}^{-1} \mathrm{~g}^{-1}$. Lot 1 had the lowest leakage of 287 and $352 \mu \mathrm{Scm}^{-1} \mathrm{~g}^{-1}$ at 16 and 24 hours, while lot 10 had the highest amount of leakage: 356 and $497 \mu \mathrm{Scm}^{-1} \mathrm{~g}^{-1}$. The difference of the leakage within eight hours between 16 and 24 hours occurred at $65 \mu \mathrm{Scm}$ ${ }^{1} \mathrm{~g}^{-1}$ in the most vigorous lot (Lot 1 ) and $141 \mu \mathrm{Scm}^{-1} \mathrm{~g}^{-1}$ in the worst lot (Lot 10) (Table 2). EC values after AA were increased at both 16 and 24 hours of measurements. Aging increased the amount of solute leakage in all seed lots. This went up to over 500 at 16 hours and $600 \mu \mathrm{Scm}^{-1} \mathrm{~g}^{-1}$ at 24 hours in lots of low vigour (Lots 8 and 10).

Seedling emergence percentages were between 63 and $85 \%$ in the first sowings and 59 and $83 \%$ in the second sowings in field conditions. Lot 1 had significantly higher emergence percentages than the rest of the lots $(p<0.05)$. Controlled room emergence (CRE) in all seed lots was higher than in the field, and ranged between 75 and $92 \%$. The values of the first four lots (lots 1-4) and lots 6-9 did not vary significantly $(p>0.05)$. In the field sowings however, differences in emergence percentages of these seed lots were significant $(\mathrm{p}<0.05)$ (Table 3$)$. For example, the first four lots had $90-92 \%$ emergence in CRE but this was 75 and $85 \%$ in the first sowing and 74 and $83 \%$ in the second sowing (Table 3). Vigour differences were more reflected in the field sowings than in CRE conditions, where the sowing environment was more unfavourable and favourable, respectively. All vigour tests with one exemption (EC16h after AA) correlated with seedling emergence in field and controlled room emergence conditions. However, the level of significance varied. The highest number of correlation was observed in RE24h and EC16h, and both vigour tests correlated to three different sowing conditions at $p=0.001$ level (Table 4). The correlation was the lowest level in SG and emergence (in two cases $\mathrm{p}<0.05$, in one case $\mathrm{p}<0.01$ ). The relationships between EC16h, RE24h and SG with first and second field sowings and controlled room emergence were shown in Fig. 1. The lower the EC16h and the higher the RE24h values, the higher the emergence not only in the field but also in CRE conditions. Initial standard germination test showed lower $R^{2}$ values $\left(R^{2}=0.37, n s ; 0.45\right.$ and $0.54, p<0.05)$ than either vigour tests in all three emergence environments.

Table 1. Standard germination (normal germination), radicle emergence percentages of 12, 24 and 36 hours after germination, mean germination time (MGT, h) of 10 commercially available cress seed lots

\begin{tabular}{|c|c|c|c|c|c|}
\hline Seed lot & $\begin{array}{c}\text { Standard Germination } \\
(\text { SG \%) }\end{array}$ & RE12h & RE24h & RE36h & MGT (h) \\
\hline 1 & $93 \mathrm{a}$ & $79 \mathrm{a}$ & $93 a$ & $97 \mathrm{a}$ & $26 a$ \\
\hline 2 & $92 \mathrm{ab}$ & $65 c$ & $89 \mathrm{~b}$ & $95 \mathrm{a}$ & $28 \mathrm{~b}$ \\
\hline 3 & $91 \mathrm{ab}$ & $65 c$ & $91 \mathrm{ab}$ & $95 \mathrm{a}$ & $26 a$ \\
\hline 4 & $91 \mathrm{ab}$ & $71 b$ & $91 \mathrm{ab}$ & $95 a$ & $26 a$ \\
\hline 5 & $90 \mathrm{bc}$ & $62 c$ & $79 \mathrm{c}$ & $90 \mathrm{~b}$ & $31 \mathrm{c}$ \\
\hline 6 & $92 \mathrm{ab}$ & $52 \mathrm{~d}$ & $73 \mathrm{~d}$ & $79 \mathrm{~cd}$ & $38 \mathrm{f}$ \\
\hline 7 & $91 \mathrm{ab}$ & $43 \mathrm{e}$ & $71 \mathrm{de}$ & $77 \mathrm{~d}$ & $38 \mathrm{f}$ \\
\hline 8 & $90 \mathrm{bc}$ & $50 \mathrm{~d}$ & $70 \mathrm{e}$ & $80 \mathrm{c}$ & $33 \mathrm{~d}$ \\
\hline 9 & $91 \mathrm{ab}$ & $50 \mathrm{~d}$ & $67 \mathrm{f}$ & $79 \mathrm{~cd}$ & $36 \mathrm{e}$ \\
\hline 10 & $88 \mathrm{c}$ & $32 \mathrm{f}$ & $60 \mathrm{~g}$ & $70 \mathrm{e}$ & $38 \mathrm{f}$ \\
\hline Range & $88-93$ & $32-79$ & $60-93$ & $70-97$ & $26-38$ \\
\hline
\end{tabular}

Means with different letters in the same column denote significant difference at $5 \%$ level

Table 2. Changes in AA test, EC after 16 (EC16h) and 24 hours (EC24h) and EC16h and EC24h after AA in 10 cress seed lots

\begin{tabular}{|c|c|c|c|c|c|}
\hline \multirow[b]{2}{*}{ Seed lot } & \multicolumn{5}{|c|}{ Electrical Conductivity $\left(\mathrm{EC}, \mu \mathrm{Scm}^{-1} \mathrm{~g}^{-1}\right)$} \\
\hline & $\begin{array}{c}\text { AA } \\
\left(45^{\circ} \mathrm{C}, 24 \mathrm{~h}\right)\end{array}$ & $\begin{array}{c}\text { EC16h } \\
\left(\mu \mathrm{Scm}^{-1} \mathrm{~g}^{-1}\right)\end{array}$ & $\begin{array}{c}\text { EC24h } \\
\left(\mu \mathrm{Scm}^{-1} \mathrm{~g}^{-1}\right)\end{array}$ & $\begin{array}{c}\text { EC16h } \\
\text { after AA }\end{array}$ & $\begin{array}{r}\text { EC24h } \\
\text { after AA }\end{array}$ \\
\hline 1 & $75 \mathrm{a}$ & $287 a$ & $352 \mathrm{a}$ & $410 a$ & $501 \mathrm{a}$ \\
\hline 2 & $77 \mathrm{a}$ & $301 \mathrm{~b}$ & $392 \mathrm{~b}$ & $447 \mathrm{~b}$ & $580 \mathrm{~d}$ \\
\hline 3 & $71 \mathrm{~b}$ & $305 b$ & $442 \mathrm{e}$ & $495 \mathrm{~d}$ & $559 \mathrm{c}$ \\
\hline 4 & $67 c$ & $317 c$ & $423 \mathrm{~d}$ & $497 \mathrm{~d}$ & $534 b$ \\
\hline 5 & $64 \mathrm{~d}$ & $334 \mathrm{~d}$ & $403 c$ & $452 \mathrm{~b}$ & $532 \mathrm{~b}$ \\
\hline 6 & $68 c$ & $340 \mathrm{de}$ & $443 \mathrm{e}$ & $492 \mathrm{~d}$ & $585 \mathrm{~d}$ \\
\hline 7 & $60 \mathrm{e}$ & $350 \mathrm{fg}$ & $480 \mathrm{~g}$ & $463 c$ & $637 \mathrm{f}$ \\
\hline 8 & $55 \mathrm{f}$ & $340 \mathrm{de}$ & $477 \mathrm{~g}$ & $520 \mathrm{e}$ & $614 \mathrm{e}$ \\
\hline 9 & $49 \mathrm{~g}$ & $343 \mathrm{ef}$ & $454 \mathrm{f}$ & $494 \mathrm{~d}$ & $612 \mathrm{e}$ \\
\hline 10 & $35 \mathrm{~h}$ & $356 \mathrm{~g}$ & $497 \mathrm{~h}$ & $528 \mathrm{e}$ & $648 \mathrm{f}$ \\
\hline Range & $35-77$ & $287-356$ & $352-497$ & $410-528$ & $501-648$ \\
\hline
\end{tabular}

Means with different letters in the same column denote significant difference at $5 \%$ level 
Table 3. Changes in field emergence percentages in two sowings and controlled room conditions of 10 cress seed lots

\begin{tabular}{|c|c|c|c|}
\hline \multirow{2}{*}{ Lot } & \multicolumn{2}{|c|}{ Field Emergence (FE) \% } & \multirow{2}{*}{$\begin{array}{c}\text { Controlled Room } \\
\text { Emergence (CRE) (\%) }\end{array}$} \\
\hline & 1. Sowing & 2. $\quad$ Sowing & \\
\hline 1 & $85 \mathrm{a}$ & $83 a$ & $92 \mathrm{a}$ \\
\hline 2 & $80 \mathrm{~b}$ & $78 \mathrm{~b}$ & $91 \mathrm{a}$ \\
\hline 3 & $78 \mathrm{~b}$ & $75 c$ & $91 \mathrm{a}$ \\
\hline 4 & $75 \mathrm{c}$ & $74 \mathrm{c}$ & $90 \mathrm{a}$ \\
\hline 5 & $73 \mathrm{~cd}$ & $73 \mathrm{~cd}$ & $84 b$ \\
\hline 6 & $72 \mathrm{de}$ & $71 \mathrm{de}$ & $81 \mathrm{c}$ \\
\hline 7 & $70 \mathrm{e}$ & $69 \mathrm{e}$ & $79 \mathrm{c}$ \\
\hline 8 & $63 \mathrm{~g}$ & $69 \mathrm{e}$ & $80 \mathrm{c}$ \\
\hline 9 & $66 \mathrm{f}$ & $63 \mathrm{f}$ & $80 \mathrm{c}$ \\
\hline 10 & $67 \mathrm{f}$ & $59 \mathrm{~g}$ & $75 \mathrm{~d}$ \\
\hline Range & $67-85$ & $59-83$ & $75-92$ \\
\hline
\end{tabular}

Means with different letters in the same column denote significant difference at $5 \%$ level

Table 4. Correlation coefficients calculated for MGT, radicle emergence after 12 (RE12h), 24 (RE24h), 36h (RE36h), electrical conductivity after 16h (EC16h), 24h (EC24h), AA (Accelerated ageing) tests. EC16h after AAT, EC24h after AAT, and standard laboratory germination (SG) as estimation of seedling emergence percentages of field emergence and controlled room conditions in cress seed lots

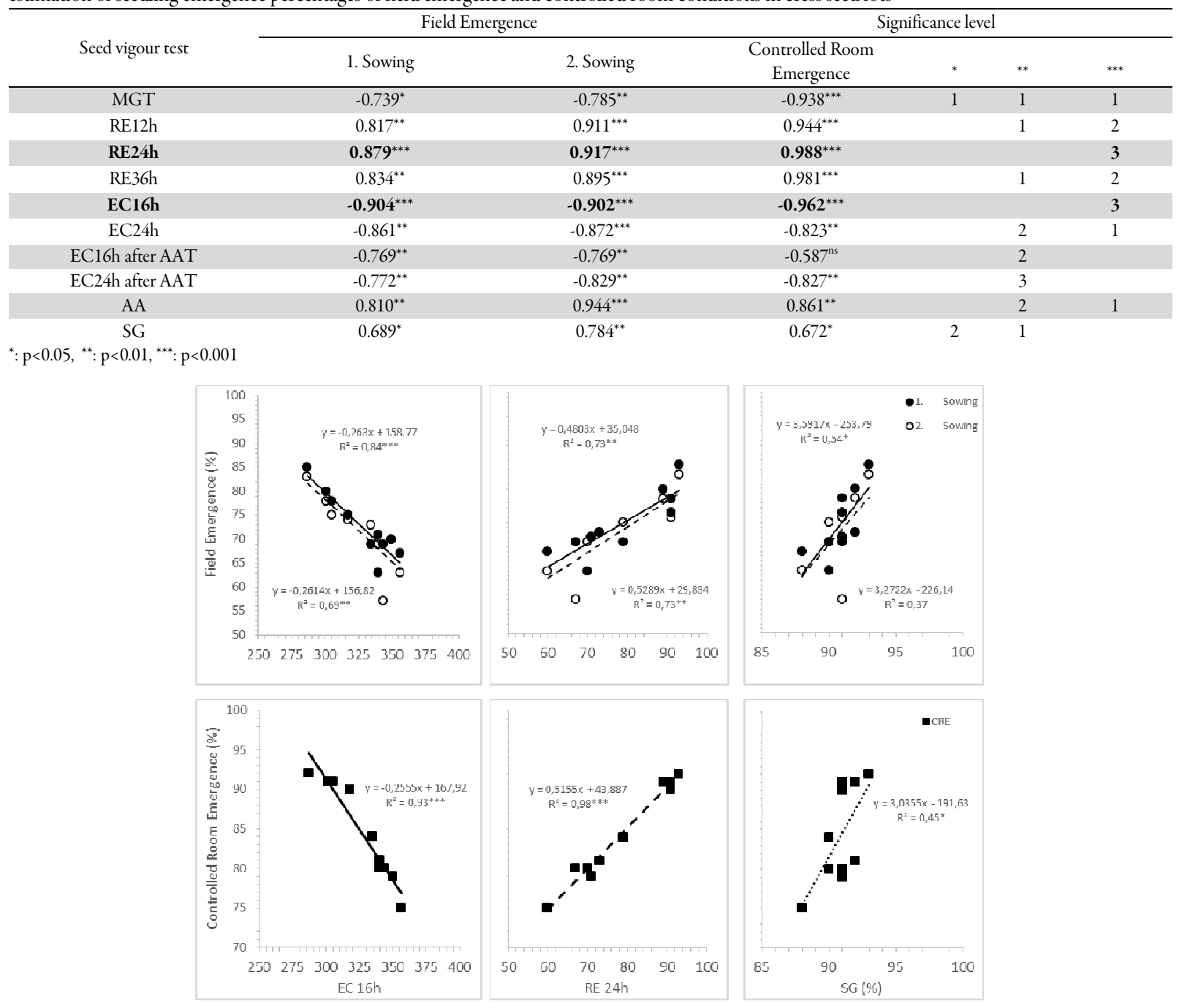

Fig. 1. Relationship between electrical conductivity of $16 \mathrm{~h}$ (EC16h), radicle emergence of $24 \mathrm{~h}$ (RE24h) and SG with field emergence in two sowings, 1 . sowing $(\bullet)$, 2. sowing $(\circ)$ and controlled room emergence $(\bullet)$ of 10 cress seed lots. Significance:*:0.05, ${ }^{* *}: 0.01,{ }^{* * *}: 0.001$ 


\section{Discussion}

The results of the present work indicated that radicle emergence counts after 24 hours (RE24h) and electrical conductivity after 16 hours ( EC16h) were highly correlated $(p<0.001)$ with seedling emergence percentages in three different sowings (two sowings of field conditions and one in controlled room conditions) (Table 4). Aside from these two tests, the other vigour tests were also related to emergence performance, but the level of significance was not as high as these two vigour tests (Table 4). The seed lots used in the experiments were selected to have acceptable levels of standard germination. Standard germination percentages were above $88 \%$. Seed deterioration had not progressed far enough to cause large reductions in standard germination (normal seedling germination). Nine seed lots out of ten had standard germination percentages of 90 and 93\%. However, differences in the seedling emergence of cress seeds at the three different sowing times with high standard germination revealed differences in seed vigour. The major cause of differences in vigour is based on pre and post-harvest practices, which when not optimum lead to seed deterioration. Mean time to germination (MGT) through periodic counts of radicle emergence is a very common measurement of rate of germination and is the first sign of aging level in any lot (Matthews and Powell, 2011). The more deteriorated (low vigour) seed lots need a longer time to germinate (higher deterioration). MGT in our work was related to seedling emergence percentages $(\mathrm{p}<$ $0.005-0.001, r=0.739-0.938$ ), which is in agreement with some earlier studies of various crop seeds (Demir et al., 2008; Mavi et al., 2010; Mavi et al., 2016). However, MGT is a relatively time-consuming measurement, since periodic counts of radicle emergence during germination test period are needed. The germination test period in some crop seeds like parsley goes up to 28 days (ISTA, 2017). Instead of producing germination curves for the calculation of MGT, a simpler method was applied by using single early counts of radicle emergence, hence vigour. This was the idea behind the radicle emergence test (RE) and was related to MGT (Mavi et al., 2016). There is clear evidence that the early single radicle emergence count during germination testing is related to seedling emergence in the field and in modules for agronomic and horticultural crop seeds (Demir et al., 2011; Matthews et al., 2012; Lv et al., 2016; Mavi et al., 2016). Our results in cress seeds (RE24h) agreed with these previous findings. Earlier studies on various crop seeds such as maize (Matthews and Khajeh-Hosseini, 2006; KhajehHosseini et al., 2010) and cucurbits (Mavi et al., 2010) indicated that time to germination relates to seedling emergence in modules and field. A relationship between mean germination time and seedling size was reported by Oakley et al. (1994) in impatiens. Dell'Aquila (1987) suggested that the first sign of seed aging in wheat is time to radicle protrusion. Matthews and Khajeh-Hosseini (2006) showed that as seeds age, they require a longer time to protrude a radicle, a period they named as the quiescent period between imbibition and radicle appearance, which is also known as the lag period. Determining seed vigour on the basis of a germination test may be advantageous, because it is a simple, routine test that does not need additional expertise or technical knowledge. It is easily reproducible and provides a quick and fast evaluation. The RE test has two main advantages. One is it provides very fast evaluation, i.e. within 2-3 days, and the second is that it can be incorporated in a routine germination test so that so it gives a saving in time and space (Powell and Matthews, 2012). The RE test is based on standard laboratory germination testing, the rules of which are internationally published, (ISTA, 2017) so that they are easy to repeat within and between laboratories. Mean germination time, in contrast, involves counting radical emergence throughout the germination, and necessitates a more intensive work load. A single count during germination at 24 hours in this work is fast and uncomplicated. Aging tests such as accelerated aging takes a minimum of 10 to 18 days (2-3 days of aging and the post-aging germination test period), which varies according to the species.

The process of aging involves the cell membrane integrity, which results in the loss of the semi-permeable feature of the cell membrane, thus inducing an increase in the solute leakage of soak water (McDonald, 1999). In legumes and maize seeds, leakage of individual seeds was determined with an automatic conductivity meter, and the results confirmed that the EC of seed leachate can be taken as a physiological index of seed germination and vigour (Steere et al., 1981; Davidson et al., 1994; Demir et al., 2012). In a recent study by our group, we found a strong relationship between germination and electrical conductivity in cress seed lots (Ozden et al., 2017). The electrical conductivity of seed soak water (EC16h) was highly related to seedling emergence in all three sowings in our study (Table 4). In all three sowings the correlation between EC16h and seedling emergence was highly significant $(\mathrm{p}<0.001, \mathrm{r}=0.902-0.962)$. The electrical conductivity test was completed in 24 hours. However, in some crop seeds like chickpeas, as short a time as two hours (Khajeh-Hosseini and Rezazadeh, 2011), or three hours in radishes (Mavi et al., 2016), can be used in prediction of seedling emergence. This could also be possible in cress seeds as well. Our intention was to use 16 hours, because it can be useful for soaking seeds overnight and making measurements the following morning. Shorter periods of measurement (e.g. two hours) may be an alternative period to run the test and is a matter for further research.

The AA test was initially developed to determine seed storage potential (TeKrony, 2003), but it has evolved into a commonly used seed vigour indicator for many large-seeded crops such as soybeans. AA has been successfully used in ranking the seed vigour of various crops (Hampton and TeKrony, 1995). AA was validated by ISTA rules for soybean seeds. Even though cress seeds are quite small in size compared to soybeans, vigour differences were detected by the AA test ( $\mathrm{p}<0.01-0.001, \mathrm{r}=0.810-0.944)$ (Table 4). This conclusion indicates that AA has a potential to be used in smaller-seeded species as well. EC readings after AA were not found successful regarding the relation to seedling emergence either as well as EC or AA test, itself (Table 4). The idea behind EC measurements after AA was that the extent of aging might have helped to discriminate seed vigour better than without AA treated ones. However, the $\mathrm{AA}$ and EC tests discriminated the seed lots well enough (Table 2). 
886

\section{Conclusions}

In conclusion, radicle emergence after 24 hours of a germination test and electrical conductivity of solute leakage of soaked seeds after 16 hours indicated the seed vigour differences amongst the lots. Both tests are quick, cheap and simple methods for testing seed vigour. Both tests were successful in all three different sowing environments, which show that they are helpful in ranking the seed lots in various adverse conditions.

\section{Conflicts of interest}

The authors declare that there are no conflicts of interest related to this article.

\section{References}

Davidson KGV, Moore FD, Roos EE, Nath S, Sowa S (1994). Comparison of seed-quality indices resulting from single-seed electroconductivity measurements. HortScience 29(10):1158-1163.

Dell'AquilaA (1987). Mean germination time as a monitor of the seed aging. Plant Physiology and Biochemistry 25:761-768.

Demir I, Ermis S, Mavi K, Matthews S (2008). Mean germination time of pepper seed lots (Capsicum annuum) predicts size and uniformity of seedlings in germination tests and transplant modules. Seed Science and Technology36(1):21-30.

Demir I, Celikkol T, Sarikamis G, Eksi C (2011). Vigor tests to estimate seedling emergence potential and longevity in Viola seed lots. HortiScience 46(3):402-405.

Demir I, Cebeci C, Guloksuz T (2012). Electrical conductivity measurements to predict germination of commercially available radish seed lots. Seed Science and Technology 40(2):229-237.

Finch-Savage WE (1995). Influence of seed quality on crop establishment, growth and yield. In: Basra AS (Ed). Seed Quality, Basic Mechanisms and Agricultural Implications. Haworth Press, Inc., New York, pp 4580.

Hampton JG, Tekrony DM(1995). Handbook of vigor test methods. The International Seed Testing Association, Zurich, Switzerland.

ISTA (2017). International Rules for Seed Testing. International Seed TestingAssociation, Bassersdorf, Switzerland.

Khajeh-Hosseini M, Nasehzadeh M, Matthews S (2010). Rate of physiological germination relates to the percentage normal seedlings in standard germination tests of naturally aged seed lots of oilseed rape. Seed Science and Technology 38(3):602-611.
Khajeh-Hosseini M, Rezazadeh M (2011). The electrical conductivity of soak-water of chickpea seeds provides a quick test indicative of field emergence. Seed Science and Technology39(3):692-696.

Lv YY, Wang YR, Powell AA (2016). Frequent individual counts of radicle emergence and mean just germination time predict seed vigour of $A$ vena sativa and Elymusnutans. Seed Science and Technology 44(1):189-198.

Marcos-Filho M (2015). Seed vigor testing: an overwiew of the pat, present and future perspectives. Scientia Agricola 72(4):363-374.

Matthews S, Khajeh-Hosseini M (2006). Mean germination time as an indicator of emergence performance in soil of seed lots of maize ( $Z e a$ mays). Seed Science and Technology 34(2):339-347.

Matthews S, Powell AA (2011). Towards automated single counts of radicle emergence to predict seed and seedling vigour. Seed Testing International 142:44-48.

Matthews S, Noli E, Demir I, Khajeh-Hosseini M, Wagner MH (2012). Evaluation of seed quality: from physiology to international standardisation. Seed Science Research 22:69-73.

Mavi K, Demir I, Matthews S (2010). Mean germination time estimates the relative emergence of seed lots of three cucurbit crops under stress conditions. Seed Science and Technology38(1):1425.

Mavi K, Powell AA, Matthews S (2016). Rate of radicle emergence and leakage of electrolytes provide quick predictons of percentage normal seedlings in standard germination tests of radish (Raphanussativus). Seed Science and Technology 44(2):393-409.

McDonald MB (1999). Seed deterioration: physiology, repair and assesment. Seed Science and Technology 27:177-237.

Oakley K, Kester ST, Geneve RL (1994). Computer-aided digital image analysis of seedling size and growth rate for assessing vigor in Impatiens. Seed Science and Technology 32(3):907-915.

Ozden E, Memis N, Kapcak D, Durmus E, Ozdamar C, Ozdemir M, Demir I (2017). Electrical conductivity relates seed germination in cress. In: Proceedings of 2nd International Balkan Agriculture Congress. Tekirdağpp 476-481.

Powell AA, Matthews S (2012). Seed aging/repair hypothesis leads to new testingmethods. Seed Technology 34:15-25.

Powell AA, Mavi K (2016). Application of the radicle emergence test to radish (Raphanussativus) seed. Method Validation Reports 65-72.

Steere WC, Levengood WC, Bondie JM (1981). An electronic analyzer for evaluating seed germination and vigour. Seed Science and Technology 9:567-576.

TeKrony DM (2003). Precision is an essential component in seed vigour testing. Seed Science and Technology 31(2):435-447. 